\title{
Understanding Organisational Culture and Organisational Performance: Are They Two Sides of the Same Coin?
}

\author{
Dr Oluwafemi Emmanuel IDOWU \\ Anglia Ruskin University, Faculty of Health, Social Care and Education, $2^{\text {nd }}$ Floor William \\ Harvey Building, Bishop Hall Lane, Chelmsford, Essex, CM1 1SQ, UK
}

Tel: 44-845-196-4759Ｅ-mail: emmanuel.idowu@anglia.ac.uk

Received: Nov. 3, 2016

doi:10.5296/jmr.v9i1.10261
Accepted: Dec. 2, 2016 Published: January 1, 2017

URL: http://dx.doi.org/10.5296/jmr.v9i1.10261

\begin{abstract}
The understanding of organisational culture is increasingly viewed as a necessary requirement for high performance in the organisation. This is also suggestive that the culture of an organisation may have a significant impact on the success of the organisation. The term 'organisational culture' is used widely, however inappropriately and occasionally defining and using it incorrectly. While there is universal agreement that organisational culture exists and that it plays a crucial role in shaping behaviour and performance in organisations, there is little consensus on what organisational culture is and how it impacts on organisational performance. Without a reasonable understanding of the concept of organisation culture and its definition, we cannot understand its relationships with organisational performance. This paper explores the notion and the understanding of the concepts of organisational culture and organisational performance. If we can define and understand the concept of organisational culture, then we can understand how it can impact on organisational performance.
\end{abstract}

Keywords: Organisational Culture, Organisational performance 


\section{Introduction}

Scholars such as Mannion et al., (2009) and Scott et al., (2006) claimed that the understanding of the concepts of organisational culture and organisational performance are paramount in order to achieve a sustainable organisational reform. For example, Scott et al., (2003; 2006) claimed that in a healthcare organisation, shared beliefs and attitudes about quality, risk and the role of patients in decision-making may be expected to influence service delivery. Thus the credence attached to notions of improving the organisational culture as a means of enhancing organisational performance in current parlance. Alvesson and Willmott (2012) suggest that the causal relationships between organisational culture and organisational performance are far from simple, with one (organisational culture) item determining the other (organisational performance). For example, Cameron and Quinn (2006) work suggests that there is a positive relationship between decentralisation and return on investment. However, they also suggest that organisational culture based upon participative decision-making correlate with below-average long-term performance. This might suggests that there is no simple causal link between the organisational culture and resulting organisational performance. Hassard (2005:13) claimed that the concept of organisational culture "is very complex, widely accepted, but not universally interpreted." Deshpande et al., (2006:3) asserted that "organisational culture has been recognised as an essential influential factor in analysing organisations in various contexts." As a result, a great deal of literature has been generated about these two concepts. However, little agreement and understanding exists over the precise definition of the two concepts and the extent to which they are related.

\section{Understanding Organisational Culture}

Organisational culture is a slippery concept to concretely define. Schein (2011:10) points out that the term "organisational culture" alludes to two "critical elements": structural stability and integration. The first element, structural stability, refers to a set of commonly held values and beliefs 'deep' within the organisation, not easily identifiable when viewing surface behaviours and practices. These deeply held values and beliefs distinguish one organisational culture from another and establish the organisation's identity. Examples might be the degree of trust in the organisation's leadership or the level of dependence or independence allowed employees within the organisation. The second element, integration, is noted by Schein as the myriad of behaviour patterns, "rituals, climates, and values" that combine to mould the organisation's identity (Schein 2011:10). He gives a detailed account of the way organisational culture evolves in an organisation. He argues that organisations are purposeful entities formed by the actions of the founders, who have strong assumptions about what to do and how to do things. He also has a strong view about the nature of the world, human nature, truth, relationships, time, and space, and he influence the way culture is formed and shared in the organisation. The important decisions made by people in an organisation are reflective of the values, beliefs and assumptions in organisational life. Therefore, when an individual becomes part of an organisation, he or she is constrained with respect to his or her choices. For example, Alvesson and Wilmott (2012) argue that people are often bound by cultural limits, even as regards the collection of information required for decision making thereby imposing limitations on their preferences for choices. 
"The way we do things around here" (Deal \& Kennedy, 2002:13) might be the most common sense and easy-to understand definition of organisational culture. However, it oversimplifies the complexity of the concept and misses powerful underlying concepts and processes. It is better to regard organisational culture as referring to the shared values, beliefs and assumptions, actions as well as artefacts and language patterns in an organisation. It should be regarded as an acquired body of knowledge about how to behave and shared meanings and symbols, which facilitate everyone's interpretation and understanding of how to act within an organisation. Some scholars further define Organisational culture as the observable behavioural rules in human interaction (House et al., 2004), and others as a consistent perception within an organisation (Alvesson, 2005). From another point of view, organisational culture might be seen as "a means of stabilising behaviour" (Hofstede, 2001:11). This view is supported by Chau (2008) who considered organisational culture as the glue that holds organisations together, a means by which participants communicate and co-ordinate their efforts, and incidentally a ring fence separating insiders from outsiders. In an allegorical view of organisational culture, a group of scholars (Mallack et al., 2003) noted that an organisational culture has to do with shared assumptions, priorities, meanings and values, with patterns of beliefs among people in organisations. Hassard (2005) see such a culture as emerging to solve problems posed by situations that people encounter in organisational settings; Parker (2007) see organisational culture as the ways in which people cope with experience.

Despite the various definitions and perspectives on organisational culture, one thing is universal amongst most of them, and that is the shared nature of the beliefs, philosophies, and norms. In essence, many claimed that the function of organisational culture is to create a feeling of 'esprit de corps' within the organisation (Handy, 2002a). If this is so, then we should attempt to examine the relationship between organisational culture and organisational performance. Schein (2011) claimed that organisational culture is a result of many factors, some of which are the type of organisational business, its products, its customers, its size and location and its methods of operating. An important point made by some scholars while exploring the concepts and definitions of organisational culture is the stress that organisational culture is a dynamic, evolving process, not at all static. Chau (2008), for example, argued that organisational culture must be understood as an active, living phenomenon through which people create and recreate their worlds. Schein (2011) also stated that organisational culture changes over time and becomes more embedded into the 'out-of-awareness' functioning of an organisation. Both Chau and Schein's views imply that key individuals have a crucial role to play in shaping and refining the organisational culture. Schein (2011:12) claimed that "organisational culture are created by leaders and one of the most decisive functions of leadership may well be the creation, the management, and - if and when that may become necessary - the destruction of culture".

Given the intuitive appeal of organisational culture, there is little agreement as to how organisational culture should be conceptualised. The term organisational culture carries different meanings for different people (Schein, 2011; Alvesson, 2005). Martin (2002) and Chau (2008) hold similar views and observe that, in spite of the numerous articles appearing 
on organisational culture, the definition and boundaries of organisational culture are often confused. Indeed, the concept has been described as "a riddle wrapped in a mystery wrapped in an enigma" (Ogbonna \& Harris, 2008:11). The multiplicity of perspectives and continued "paradigm wars" have led one scholars to comment that the organisational culture field mirrors the "king of the mountain" game, where, "one king temporary triumph at the top of the sand pile is rapidly superseded by the reign of another would be monarch, until a succession of short-lived victories and a plethora of defeats leave the pile flattened" (Martin et al., 2006:4). Alvesson and Wilmott (2012) argue that one reason for this is the difference in the anthropological origins of the concept, where there are differing views on organisational culture. Hence the notions of meaning, interpretation and symbolic significance are important in understanding organisational culture as a concept (Alvesson, 2005). Meaning refers to how objects (artefacts and utterances) are interpreted, which shapes our relationships with them. A symbol is an object that stands ambiguously for something else or more than something else (Marcoulides \& Ronald, 1993). Symbols must be interpreted to grasp what they represent. Organisational culture from this perspective becomes a process of interpretation and importantly a collective process which takes place in "a shared frame of reference of beliefs, expressive symbols and values" (Chau, 2008:9).

The concept of organisational culture is valued for organisational analysis purposes and the right organisational culture is considered to be a requirement for high levels of organisational performance (Fey \& Denison, 2003). Schein (2011:39) asserted that "organisational analysts hold varying conceptions of organisational culture", a point reiterated by other theorists, for example Alvesson (2005). The importance of the concept of organisational culture for theorists and practitioners and the varied definitions of it have direct implications for understanding organisational performance. At the heart of the complexity of the notion of organisational culture is the range of different ontological underpinnings of organisational culture, with the complication that, as Alvesson (2005) points out, these underpinnings are not fixed and there is a tendency to drift between them. Further, even within the same ontological understanding of the concept, the managerial implications may be different. Thus it is possible to hold realist views which argue that organisational culture is created by 'organisational performance' at the same time have to believe that it is not. There is the assumption that changing the culture of an organisation in a pre-determined direction will lead to improvements in performance (Deninson et al., 2004). Although such an assertion feels correct intuitively, the relationship between the organisational culture and organisational performance is problematic both conceptually and in practice.

\section{Understanding Organisational Performance}

Hartog and Verburg (2004) define performance as the degree of achievement of the mission at work place that builds up an employee job. Daft (2000) claimed that organisational performance is the organisation's capacity and capability to accomplish its goals effectively and efficiently. Schultz and Hatch (1996) also define organisational performance as the achievement of the organisational goals and objectives. House et al., (2004) define organisational performance as the degree of achievement of the mission at workplace that builds up an employee job, while Mahal (2009) claimed that organisational performance is 
the organisation's capacity and capability to accomplish its goals effectively and efficiently. Denison et al., (2004) mentioned that efficiency and high performance is any organisation goal and to understand organisational performance, one has to examine and understand organisational culture. Hartnell et al., (2011:6) claimed that the strongest component of the word "organisational culture" is the values, beliefs and attitudes of the employees. It is the people who make up the organisational culture, he stated. For example, if an organisational culture norms contain beliefs such as, 'Around here, nobody dares make waves' or 'Do just enough to get by and people will leave you alone', the organisational performance will reflect those values, beliefs and assumptions. Moreover, if the cultural belief system contains positive approaches, such as, 'Winners are rewarded here' or 'People really care if you do a good job in this organisation', that also will be reflected in the organisational performance.

Hartnell et al., (2011) stated that an organisation's cultural norms strongly affect all who are involved in the organisation. Those norms are almost invisible, but are necessary to understand and improve performance. Hartnell et al., (2011:9) in his study, explored employee beliefs and attitudes, and relate it to the question, "How are things done in the organisation?" He tried to answer the question by stating that knowing these attitudes and norms will make it possible to understand organisational culture and its relationship with organisational performance. Hartnell et al., (2011) in the strongest terms claimed that there is inconsistency in the literature regarding the relationships between organisational culture and organisational performance. For example, he referred to the work of Denison et al., (2004) where they linked management practices in their studies with the underlying assumptions and beliefs, that it was an important but often neglected step in the study of organisation. Hartnell et al., (2011) found that performance was a function of values, beliefs and assumptions held by the members of the organisation. He postulated that an organisation that had a 'strong culture' was defined to be of widely 'strong shared values among its employees'. The strength with which the cultural values were held among its employees was then taken to be the predictor of future organisational performance. This was usually measured financially. In a similar vein, a study of Gordon and DiTomaso (1992) found supporting evidence that a 'strong culture' was predictive of short-term organisational performance. Peters and Waterman (1982) claimed that high performance organisations could be distinguished from low performance organisations because they possessed certain cultural traits and 'strong culture'. Similarly, Deal and Kennedy (2002) suggested that organisational performance can be enhanced by 'strong' shared values. However, their suggestions were criticized by Ogbonna and Harris (2008), Chau (2008), and Mallack et al., (2003) who commented that 'a simple model' relating organisational culture to organisational performance no longer fits a more sophisticated understanding of the tie between organisational culture and organisational performance. Organisational culture has been the most important issue for leaders to know which factors influence an organisational performance in order for them to take appropriate steps to initiate them. However, defining, conceptualising, and measuring performance have not been an easy task.

Chau (2008) define organisational performance as the organisation's ability to attain its goals by using resources in an efficient and effective manner. While Denison et al., (2004:5) 
defined organisational performance "as the ability of the organisation to achieve its goals and objectives". Organisational performance has suffered, just like organisational culture, from not only a definition problem, but also from a conceptual problem. Martin et al., (2006) stated that as a concept in modern management, organisational performance suffered from problems of conceptual clarity in a number of areas. The first was the area of definition while the second was that of measurement. The term 'performance' was sometimes confused with productivity. According to Chau (2008), there was a difference between performance and productivity. Productivity was a ratio depicting the volume of work completed in a given amount of time. Performance was a broader indicator that could include productivity as well as quality, consistency and other factors. In result oriented evaluation, productivity measures were typically considered.

Additionally, organisational performance has also been conceptualized using financial and non financial measures from both objective and perceptual sources. Objective measures include secondary source financial measures such as return on assets, return on investment, and profit growth. Financial measures enable researchers to construct trend analyses and benchmarking analyses (Lund, 2003). Perceptual sources include employee evaluations of organizational effectiveness or financial health and their overall level of satisfaction. These subjective assessments of performance frequently have been used in organizational theory to evaluate organisational performance and overall employee satisfaction. Given the increasing pressure of organizations to satisfy multiple stakeholder groups, there is a need for more complex measures of organisational performance in which overly simplistic single variable models are inadequate expressions of the real world, multi-goal existence of organizations (Fey \& Deninson, 2003).

Defining organisational performance presents problems, as there exists, for any organisation, a range of possible performance measures. This is true especially of healthcare organisations, with measures of clinical processes, health outcomes, access, efficiency, productivity and employee variables all offering some potential (Mannion et al., 2009; Scott et al., 2003, 2006). Fey and Denison (2003:19) claimed that the essential ambiguity of organisational performance arises from three main senses of the nature of performance, performance as "enacted behaviour", relating to socio-technical processes of care, performance measured in terms of "end-points or outcomes", and performance as a "dramatic event". Each of these meanings tends to invoke the other two, as befits the nature of signification in general. Scott et al., (2006) claimed, for instance, that in a healthcare organisation, a surgical procedure in the hospital implies a technical performance and a desired outcome, as well as entailing aspects of dramatic production and presentation. A consultant's ward round is a ceremony vehicle for demonstrating important social and technical competencies, including diagnostic skill, communication, therapeutic knowledge and learning.

\section{Are the two concepts described above two sides of the same coin?}

Schein (2011) claimed that a 'strong' organisational culture means that people within the organisation tend to have similar beliefs and behaviour patterns. Deal and Kennedy (2002) asserted that a 'strong' culture enables employee to feel better about what they do, so they are 
more likely to work harder. Fey and Dennison (2004) stressed that the strength of organisational culture is an important factor in determining the organisational performance. 'Strong' culture is said to exist where staff respond to stimulus because of their alignment to organizational values (Cameron \& Quinn, 2006). In such environments, strong cultures help organizations operate like 'well-oiled' machines, engaging in outstanding execution with only minor adjustments to existing procedures as needed. Conversely, there is 'weak' culture where there is little alignment with organizational values, and control must be exercised through extensive procedures and bureaucracy (Cameron \& Quinn, 2006). Cameron and Quinn (2006) stressed that organizations that foster 'strong' cultures have clear values that give employees a reason to embrace the culture.

Where culture is strong, people do things because they believe it is the right thing to do, and there is a risk of another phenomenon, groupthink. "Groupthink" was described by Cameron and Quinn (2006) as "a quick and easy way to refer to a mode of thinking that people engage when they are deeply involved in a cohesive in-group, when the members' strivings for unanimity override their motivation to realistically appraise alternatives of action. p. 9" This could occur, for example, where there is heavy reliance on a central charismatic figure in the organization, or where there is an evangelical belief in the organization's values, or also in groups where a friendly climate is at the base of their identity. In fact, groupthink is very common and happens all the time, in almost every group. Members that are defiant are often turned down or seen as a negative influence by the rest of the group because they bring conflict.

Furthermore, Ogbonna and Harris (2008) suggested that one of the important consequences of the 'strong' organisational culture is its influence on the performance of the organisation. Although all organisations have cultures, some appear to have stronger, more deeply rooted cultures than others. Initially, a 'strong' organisational culture was conceptualised as a coherent set of beliefs, values, assumptions, and practices embraced by most members of the organisation (Alvesson, 2005). A 'strong' organisational culture involves such factors as increased consensus around strategic direction (Alvesson, 2005), heightened employee productivity (Denison et al., 2004), and enriched employee engagement and commitment (Schein, 2011).

I am of the view that organisational culture plays at least three important roles in its relationship and influence on organisational performance. First, organisational culture forms a collective identity that helps its members associate themselves with the organisation's practices, and feel themselves a part of its success. Secondly, 'strong' share culture and values help employees work together to meet stakeholders' needs and respond to external pressure. Lastly, the commitment of the employee to the primary tasks of the organization, may influence the behaviour of the employee and invariably may determine the dominant culture present in that organisation. This commitment generates shared feelings of working toward common goals. That is, organisations can achieve high performance only when employees share values. In essence, organisational culture, depending on variables like type and strength of the organisational culture will determine the organisational performance. Therefore understanding and knowing the culture of the organisation can help managers to 
understand how to manage the intensity and commitments of the employee to its core values and dominant culture. Alvesson (2005) asserted that organisational performance is related to the consistency and strengths of the organisational culture. It is therefore my assertion and in other to answer this article question, the 'face' of the organisational culture will determine the 'face' of organisational performance, hence organisational culture and organisational performance are two sides of the same coin.

\section{Conclusion}

Quick (1992) have found the significance of organisational culture in performance improvement in his work. Fey and Denison (2003) claimed that regardless of the size, industry, type or age of an organisation, organisational culture affects many aspects of organisational performance, including financial performances, innovation, customer and employee satisfaction. Deshpande et al (2006) found that higher levels of business performance were most closely related with the right type of organisational culture. They also came up with an important discovery claiming that the most successful organisations shared the competitive, achievement-oriented culture. The proposition that organisational culture (however define) and organisational performance (in all its variety) are linked has enduring intuitive appeal. Mallack et al., (2003) is suggesting that, it is common sense to assume that organisational culture will have an impact on actions taken in an organisation and that this in turn will lead to an influence on organisational performance.

\section{References}

Alvesson, M. (2005). Understanding Organisational Culture, ( $3^{\text {rd }}$ edition). London, Sage Publication.

Alvesson, M., \& Willmott (2012). Making Sense of Management, A Critical Introduction, $2^{\text {nd }}$ edn. London, Sage.

Cameron, K.S., \& Quinn, R.E. (2006). Diagnosing and Changing Organisational Culture, Based on the Competing Values Framework. San Francisco, Jossey-Bass.

Chau, V.S. (2008). The relationship of strategic performance to team strategy, company performance and organizational effectiveness. Team Performance Management, 14, 113-117. https,//doi.org/10.1108/13527590810883398

Deal, T.E., \& Kennedy, A.A. (2002). Corporate Cultures. Reading, M A; Addison - Wesley.

Denison, D. R., Haaland, S., \& Goelzer, P. (2004). Corporate culture and organizational effectiveness, Is Asia different from the rest of the world. Organisational Dynamics, 33(1), 98-109. https,//doi.org/10.1016/j.orgdyn.2003.11.008

Deshpande, R., Farley, J.U., \& Webster, F.E. (2006). Corporate Culture, Customer Orientation and Innovativeness in Japanese Firms, a quadrad analysis. Journal of Marketing, 57(1), 23-27. https,//doi.org/10.2307/1252055 
Fey, C. F. and Denison, D. R. (2003). Organisational culture and effectiveness, Can American theory be applied in Russia. Organisation Science, 14(6), 686-706. https,//doi.org/10.1287/orsc.14.6.686.24868

Goddard M., Mannion R., \& Smith P.C. (1999). Assessing the performance of NHS hospital Trusts, the role of 'hard' and 'soft' Information. Health Policy, 48, 119-134. https,//doi.org/10.1016/S0168-8510(99)00035-4

Gordon, G.G., \& Di Tomaso, N. (1992). Predicting corporate performance from organisational culture. Journal of management Studies, 29, 783-798. https,//doi.org/10.1111/j.1467-6486.1992.tb00689.x

Handy, C.B. (2002a). The Age of Unreason, New Thinking for a New World. London, Arrow Books.

Hartnell, C.A., Ou, A.Y., \& Kinicki, A. (2011). Organisational culture and organizational effectiveness, A meta-analytic review. Journal of Applied Psychology, 96, 677-694. https,//doi.org/10.1037/a0021987

Hartog, D., \& Verburg, R. (2004). High performance work systems, organizational culture and firm effectiveness. Human Resource Management Journal, 14(1), 55-78. https,//doi.org/10.1111/j.1748-8583.2004.tb00112.x

Hassard, J. (2005). Temporal metaphors in the study of organizations. Research Workshop on Historical Time Organisational Histories, Queen Mary College, London, $26^{\text {th }}$ January 2005.

Hofstede, G. (2001). Culture's Consequences, Comparing values, behaviours, institutions and organizations across nations. London, England, Sage. https,//doi.org/10.1177/017084069801900305

Hofstede, G. (1998a). Attitudes, Values and Organisational Culture, Disentangling the Concepts. Organisational Studies, 19(3), 477-492.

House, R.J., Hanges, P.J., Javidan, M., Dorfman, P.W., \& Gupta, V. (2004). Culture, Leadership and Organisations, The GLOBE Study of 62 societies. Thousand Oaks, CA, Sage Publications.

Lund, D. (2003). Organisational Culture and Job satisfaction. Journal of Business and Industrial Marketing, 18(3), 219-36. https,//doi.org/10.1108/0885862031047313

Mahal, P. (2009). Organisational culture and organisational climate as a determinant of motivation. Journal of Management Research, 8(10), 38-51.

Mallack, L.A., David, M., Susan, D., \& Frank J. (2003). Diagnosing culture in healthcare organisation using critical incidents. International Journal of Health Care Quality Assurance, 16(4), 180-90. https,//doi.org/10.1108/09526860310479668

Mannion, R., Davies, T.O. and Martin N. M. (2009). Cultures for Performance in Healthcare. Maidenhead, UK, Open University Press. 


\section{Macrothink}

Journal of Management Research

ISSN 1941-899X 2017, Vol. 9, No. 1

Marcoulides, A., \& Ronald, H.H. (1993). Organisational culture and performance, proposing and testing a model. Organisational Science, 4, 209-224. https,//doi.org/10.1287/orsc.4.2.209

Martin, J. (2002). Organisational Culture, Mapping the Terrain. London; Sage. https,//doi.org/10.4135/9781483328478

Martin, J., Frost, P., \& O’Neill, O. A. (2006). Organisational culture, Beyond Struggles for Intellectual Dominance. In, Clegg. S., Hardy. C., Lawrence. T. and Nord. W. Ed. The Handbook of Organisation Studies. $2^{\text {nd }}$ ed. Thousand Oaks, CA, Sage.

Ogbonna, E., \& Harris, L.C. (2008). Leadership style, organizational culture and performance, Empirical evidence from UK Companies. International Journal of Human Resource Management, 11, 766-788. https,//doi.org/10.1080/09585190050075114

Parker, M. (2007). Organisational Culture and Identity, Unity and Divison of Work. London, Sage.

Peters, T.J., \& Waterman, R.H. (1982). In Search of Excellence. London, Harper and Row.

Quick, J.C. (1992). Crafting an organizational culture, Herb's hand at southwest airlines. Organizational Dynamics, 21(2), 45-56. https,//doi.org/10.1016/0090-2616(92)90063-S

Schein, E. H. (2011). The Corporate Culture Survival Guide, Sense and Nonsense about Cultural Change. San Francisco, Jossey-Bass Publishers.

Schultz, M., \& Hatch, M. (1996). Living with multiple paradigms, the case of paradigm interplay in organizational culture studies. Academy of Management Review, 21(2), 529-557.

Scott, J.T., Mannion, R., Davies, H.T.O., \& Marshall, M.N. (2006). The quantitative measurement of organisational culture in healthcare, What instruments are available? Health Services Research, 9(5), 76-83.

Scott T., Mannion R., Davies, H., \& Marshall, M. (2003). Does organisational culture influence healthcare performance? Journal of Health Services Research Policy, 34(9), 11-13.

Stahl, G.K., \& Voigt, A. (2008). Do cultural differences matter in mergers and acquisitions? A tentative model and examination. Organisation Science, 19, 160-176. https,//doi.org/10.1287/orsc. 1070.0270 